\title{
Thyroid hormone action in metabolic regulation
}

\author{
Yiyun Song, Xuan Yao, Hao Ying ${ }^{\bowtie}$
}

Key Laboratory of Nutrition and Metabolism, Institute for Nutritional Sciences, Shanghai Institutes for Biological Sciences, Graduate School of the Chinese Academy of Sciences, Chinese Academy of Sciences, Shanghai 200031, China

$\bowtie$ Correspondence: yinghao@sibs.ac.cn

Received March 18, 2011 Accepted April 24, 2011

\begin{abstract}
Thyroid hormone plays pivotal roles in growth, differentiation, development and metabolic homeostasis via thyroid hormone receptors (TRs) by controlling the expression of TR target genes. The transcriptional activity of TRs is modulated by multiple factors including various TR isoforms, diverse thyroid hormone response elements, different heterodimeric partners, coregulators, and the cellular location of TRs. In the present review, we summarize recent advance in understanding the molecular mechanisms of thyroid hormone action obtained from human subject research, thyroid hormone mimetics application, TR isoform-specific knock-in mouse models, and mitochondrion study with highlights in metabolic regulations. Finally, as future perspectives, we share our thoughts about current challenges and possible approaches to promote our knowledge of thyroid hormone action in metabolism.
\end{abstract}

KEYWORDS thyroid hormone, thyroid hormone receptor, metabolic regulation, central and peripheral effect, thyroid diseases

\section{OVERVIEW OF THYROID HORMONE AND THYROID HORMONE RECEPTORS}

Thyroid hormone is critical for normal growth, differentiation, development and maintenance of metabolic homeostasis (Yen, 2001). The concept that thyroid hormone influences diverse metabolic pathways, which are important for lipid and glucose metabolism, has been recognized for decades. Thyroid hormone mimetics have been developed since thyroid hormone can lower cholesterol, improve serum lipid profiles and treat obesity. Although some thyroid hormone mimetics have already been used in human trials, we still do not understand the exact molecular mechanism due to the complex physiological effects of thyroid hormone.

There are two principal thyroid hormones: thyroxine (T4, L3,5,3',5'-tetraiodothyronine) and triiodothyronine (T3, L-3,5,3'triiodothyronine). The biologically active form of thyroid hormone is T3, whereas T4 is the most abundant thyroid hormone in the blood. In target tissues, type I or type II 5'deiodinase (DI or DII) catalyzes the deiodination of T4 and controls the local T3 concentration in cells (Braverman et al., 1970; Köhrle, 2000).

The physiological function of thyroid hormone is mainly carried out by its receptors-thyroid hormone nuclear receptors (TRs) in nucleus. TRs belong to the nuclear receptor superfamily, act as ligand-inducible transcription factors, and occupy a central position in mediating the action of T3. TRs bind to specific cis elements called thyroid hormone response elements (TREs) which are located in the promoter of target genes as homodimers or heterodimers with retinoid $X$ receptor $(R X R)$ (Cheng, 2000). The transcription mediated by TRs requires extensive cooperation and dynamic interplay with many nuclear receptor coregulators (McKenna et al., 1999; Yen, 2001).

\section{MOLECULAR MECHANISMS UNDERLYING THE TRANSCRIPTIONAL REGULATION BY THYROID HORMONE RECEPTORS}

The transcriptional activity of TRs is regulated at multiple levels. This review will provide an overview of the molecular mechanisms underlying the regulation, such as the diversity of TR isoforms, various TREs, different heterodimeric partners, a host of coregulators, and the cellular location of TR. 


\section{Thyroid hormone receptor isoforms}

Human TRs are encoded by two genes, TR $\alpha$ and TR $\beta$ (official name THRA and THRB), located on chromosomes 17 and 3 , respectively (Sap et al., 1986; Weinberger et al., 1986). TRs are composed of several functional domains: A/B domain, $C$ domain (DNA binding domain, DBD), D domain (hinge domain), and $\mathrm{E}$ domain (ligand binding domain, LBD). Among the TR isoforms, the sequences of DBD and LBD are highly conserved. However, no similarity exists in the A/B domain between TR $\alpha$ and TR $\beta$ isoforms (Cheng, 2000). The $\mathrm{TR} \alpha$ gene encodes three TRa isoforms, TR 1 1, TRa2, and TRa3, which differ in their carboxyl terminus due to alternative splicing. TRa1 is able to bind to T3 and activate or repress target genes, whereas TRa2 and TRa3 lose T3 binding capacity and antagonize T3 action (Izumo and Mahdavi, 1988; Mitsuhashi et al., 1988; Macchia et al., 2001). The TR $\beta$ gene encodes three TR $\beta$ isoforms, TR $\beta 1$, TR $\beta 2$, and TR $\beta 3$, which differ in their amino terminus. All TR $\beta$ isoforms are able to bind to their cognate ligand T3 with high affinity to mediate target gene transcription (Hodin et al., 1989). As for the distribution of TRs, TRa1 is abundantly expressed in the skeletal muscle, heart, and brown adipose tissue (BAT), whereas TR $\beta 1$ is more expressed in the liver, brain, and kidney. TR $\beta 2$ has a more restricted expression pattern, which is only expressed in the anterior pituitary and hypothalamus. TR $\beta 3$ is predominantly expressed in the kidney, liver and lung. The tissue-specific distribution of TR isoforms regulates thyroid hormone actions in different target tissues (Hodin et al., 1990; Cook et al., 1992; Yen et al., 1992; Bradley et al., 1994; Branco et al., 1999), which will be further discussed in the following text.

\section{Thyroid hormone response elements}

Analysis of the TREs in the promoter region of T3 target genes has revealed a core consensus sequence of the half site $[(A / G) G G T(C / A / G) A]$. The half sites can be arranged as an everted repeat (as in the chicken lysozyme gene), as a direct repeat (as in the malic enzyme gene) or as an inverted repeat (palindrome, as in the growth hormone gene) with 4 bps between the two half sites (DR4) (Forman et al., 1992; Cheng, 2000). To be noted, direct repeats are the most popular arrangement of TRE half sites. The ability of TR to recognize the consensus sequence of the half site in different arrangements provides a means to achieve diversity and selectivity for TRs to distinguish different T3 target genes. In vitro studies also indicated that the binding of TR to TRE is TR isoform-, TRE- and T3-dependent (Meier-Heusler et al., 1995; Zhu et al., 1997). However, other consensus sequences of TRE have been identified. In addition, several studies indicate that negative TRE exists, but its consensus sequence has not been identified.

\section{Heterodimeric partners}

Transcriptional activity of TR could be modulated by heterodimeric partners. In vitro experiments show that heterodimerization with RXR significantly increases the binding of TRs to TREs and stimulates transcription (Zhang and Pfahl, 1993). In addition to RXR, other nuclear receptors, such as peroxisome proliferator-activated receptors (PPARs) and vitamin $D$ receptor (VDR), have also been shown to heterodimerize with TRs (Bogazzi et al., 1994; Schräder et al., 1994). Three amino acids located in the $D$ box in the DBD of TRs have been demonstrated to be essential for heterodimerization and responsible for isoform-dependent protein interaction as well as DNA binding sequence specificity. Thus, heterodimerization not only provides an additional means to regulate the actions of TR, but also provides a way to crosstalk with other receptors. The polarity of the TR heterodimer is determined by the sequence, spacing, and arrangement of the half-site binding motifs. Significantly, the polarity of the heterodimer affects the ligand responsiveness, thereby modulating the ligand-dependent transcription (Zhang and Pfahl, 1993). Therefore, an additional regulation of the transcriptional activity of TR is achieved via this polaritydependent ligand responsiveness.

\section{Coregulators}

Recently, growing evidence has demonstrated that a host of coregulators participate in the diverse effects of TRs (McKenna et al., 1999). Similar to TRs, these coregulators are expressed in a tissue-specific and developmentally regulated manner. Some of these coregulatory proteins function as histone acetyltransferases (HATs) or histone deacetylases (HDACs), which are capable of remodeling the structure of chromatin through acetylation or deacetylation of histone tails. The chromatin DNA becomes more accessible to polymerase II for efficient transcription if the terminal lysine residues of the histones are acetylated by HAT. On the contrary, if the acetyl groups are removed by HDAC, the chromatin becomes more compact and more difficult to access by polymerase II, which will lead to transcriptional repression.

To date, two types of coregulators, corepressors and coactivators, have been characterized. Unlike other steroid hormone receptors, TR sits on TRE and inhibits transcription in the absence of ligand, which is referred to as basal repression. Recent discoveries have indicated that corepressors such as nuclear receptor corepressor (NCoR) and its homolog, silencing mediator of retinoid and thyroid hormone receptor (SMRT), only bind to TR in the absence of T3 and subsequently recruit $\mathrm{mSin} 3$ and HDAC1 to repress transcription. These results suggest that deacetylation of the chromatin is a pivotal step involved in such basal repression (Chen and Evans, 1995; Hörlein et al., 1995; Nagy et al., 1997). Conversely, coactivators enhance the liganddependent transcriptional activity of TR. Upon binding of T3, TR undergoes dramatic structural changes (Wagner et al., 1995). These conformational changes result in dissociation 
of corepressor complex from TR. In vitro and in vivo evidence suggests that T3-occupied TR is capable of binding to coactivators, including steroid receptor coactivators (SRCs), Trip-1, CBP/p300, and TRAP coactivator complex, which have been shown to have HAT activity or be able to recruit HAT. The recruitment of coactivator or coactivator complex leads to chromatin remodeling and transcriptional activation (Cheng, 2000; Yen, 2001). The discovery of the diverse coactivator complexes has added another layer of complexity to the transcriptional regulation by TR.

\section{Cellular location of thyroid hormone receptor}

Unlike other steroid hormone receptors, the translocation of TR from cytoplasm to nucleus was less studied. This probably is due to technical difficulties because most immortalized cell lines lose the expression of endogenous TR, while overexpression of exogenous TR always results in expression leaking in cytoplasm. Studies revealed that T3 induces TR $\beta 1$ to translocate to the nucleus; meanwhile, the phosphorylation of TR $\beta 1$ is dramatically induced by T3 (Ting et al., 1997; Ting and Cheng, 1997). The phosphorylation and translocation of TRß1 enhances its binding to TREs and increases its transcriptional activity.

Recently, TRs were identified in the mitochondrial matrix, suggesting the translocation of TRs into mitochondria is important for thyroid hormone actions on the mitochondrial genome. These studies revealed that $\mathrm{N}$-terminal truncated forms of the TR $\alpha 1$ and TR 1 are able to be imported into the mitochondrion and induce the transcription of mitochondrial genome (Wrutniak et al., 1995; Andersson and Vennström, 1997; Casas et al., 1999). Authentic TRE was identified in an element of the mitochondrial genome, which was referred to as D-loop. For example, general mitochondrial transcription factor A promoter contains D-loop. TREs were also found in the promoter region of mitochondrial genes encoding the $12 \mathrm{~S}$ and 16S rRNA in mitochondria (Wrutniak et al., 1995). The Nterminal truncated TRa1 is able to regulate the global mitochondrial transcription and control the mitochondrial replication (Pagliarini et al., 2008; Wagner et al., 2008). However, the molecular mechanisms underlying the regulation of importation of TRs into mitochondrion remain unclear.

\section{THYROID HORMONE ACTION IN METABOLIC REGULATION}

As mentioned earlier, thyroid hormone has profound effects on many physiologic processes, including development, growth and metabolism. Thyroid hormone deficiency is not compatible with health. Here we focus on thyroid hormone effects on the metabolic regulation. Our knowledge mainly comes from several aspects including human subject research, thyroid hormone mimetics and their application, knock-in mouse models, and mitochondrion study.

\section{Human subject research}

The effects of thyroid hormone have been delineated by studies in human subjects with deficient or excessive thyroid hormone levels. Hypothyroidism results from any condition that leads to thyroid hormone deficiency, while hyperthyroidism refers to the conditions with over secretion of thyroid hormone. Resistance to thyroid hormone (RTH) is a syndrome in which patients have hyposensitivity to thyroid hormone, elevated circulating serum T3 and T4, and elevated or nonsuppressed thyroid stimulating hormone (TSH) levels. The clinical manifestations of RTH patients are variable among families. It is noteworthy that RTH patients can have clinical symptoms that have features of both hypothyroidism and hyperthyroidism, suggesting variable resistance in different tissues.

\section{Hyperthyroidism}

In hyperthyroid subjects, fasting hyperinsulinemia is frequently seen. Animal studies have revealed that hyperthyroid animals develop elevated plasma glucose and insulin levels, due to increased hepatic glucose production including increased gluconeogenesis and glycogenolysis (Raboudi et al., 1989), and decreased glucose clearance and disposal. In human patients with Grave's hyperthyroidism, glucose tolerance is impaired (Randin et al., 1985). Hyperthyroidism is also accompanied by increased glucagon levels and growth hormone secretion, which may contribute to increased glucose level and decreased glucose tolerance. Further extensive metabolic evaluation has demonstrated that hyperthyroidism is characterized by (1) hyperinsulinemia after oral glucose administration, (2) increased basal hepatic glucose production, (3) impaired insulin suppression of hepatic glucose production, and (4) compromised insulinstimulated peripheral glucose utilization (Shen et al., 1988).

\section{Hypothyroidism}

In contrast to that in hyperthyroidism, hepatic glucose production is reduced in hypothyroid animals (Okajima and Ui, 1979). However, the hypothyroidism in rodents is accompanied by insulin resistance. This might be caused by decreased glucose utilization and turnover in both skeletal muscle and adipose tissue (Cettour-Rose et al., 2005). Controversial results were reported in the research of insulin sensitivity in hypothyroid human subjects (Jackson et al., 1970; Dimitriadis et al., 2006). Thus how or whether the glucose metabolism is impaired in hypothyroid humans remains unclear. 
Resistance to thyroid hormone

Increased circulating free fatty acid levels and accumulation of triglyceride and diacylglycerol (DAG) in muscle are found in $\mathrm{RTH}$ patients. A recent report indicates that the homeostatic model assessment of insulin resistance (HOMA-IR) is significantly higher in RTH patients than control subjects, suggesting a reduction of whole-body insulin sensitivity. The insulin sensitivity index (ISI) also tends to be lower in a smaller subset of RTH subjects with higher intramyocellular lipid (IMCL) content. Increased IMCL content may contribute to the insulin resistance in these RTH patients (Krssak et al., 1999; Hwang et al., 2001; Sinha et al., 2002). However, RTH subjects have increased muscle mitochondrial uncoupling and fatty acid oxidation which may improve insulin sensitivity. This discrepancy probably is due to the net accumulation of IMCL and DAG caused by increased lipogenesis or enhanced delivery of free fatty acid to skeletal muscle which exceeds the oxidative capacity (Oppenheimer et al., 1991; Petersen et al., 1994; Petersen et al., 1995). Another possibility is that the RTH action might influence hepatic insulin sensitivity. This hypothesis is supported by a recent report suggesting that T3responsive genes account for most of the dysregulated transcripts in the livers of obese and insulin resistant subjects (Pihlajamäki et al., 2009).

Taken together, these findings demonstrate that pathological alterations in circulating thyroid hormone levels lead to complex effects in multiple tissues (Table 1).

\section{Application of thyroid hormone and its mimetics}

Thyroid hormone has beneficial effects such as lowering cholesterol, improving serum lipid profiles and treating obesity. It has been known for decades that employment of thyroid hormone can affect the physiological index of the whole body. However, deleterious effects of excess thyroid hormone on heart, muscle, and bone limit its therapeutic application. In a recent population-based study of euthyroid subjects, levels of free T4 were significantly inversely related to the blood levels of triglyceride and cholesterol, blood pressure, abdominal obesity, and insulin resistance (Roos et al., 2007). This suggests that at least within the normal range of thyroid function, thyroid hormone may exert beneficial effects on components of the metabolic syndrome. Later studies have revealed that TRa1 regulates heart function, while TR $\beta 1$ plays a major role in the regulation of serum cholesterol levels and hypothalamus-pituitary-thyroid axis. To avoid the adverse effect, thyroid hormone mimetics with receptor subtype-selective activities have been developed over the past decade which also helps us to understand the mechanism of TR actions.

Thyroid hormone mimetics are capable of improving lipid profiles by reducing low density lipoprotein (LDL)-cholesterol, increasing high density lipoprotein (HDL)-cholesterol reuptake, stimulating reverse cholesterol transport, and decreasing plasma triglyceride. There are several possible mechanisms or steps contributing to these beneficial effects (Fig. 1). Thyroid hormone mimetics could: (1) increase the uptake of LDL from serum by inducing LDL receptor expression in the liver; (2) inhibit the expression of sterol regulatory element-binding protein 1 (SREBP1), a key transcription factor regulating genes required for fatty acid synthesis and conversion from very low density lipoprotein (VLDL) to LDL in circulation; (3) increase HDL reuptake by increasing the expression of HDL receptor (SRB1); (4) increase nascent HDL particle synthesis by increasing the synthesis of ApOA1; (5) increase conversion rates of cholesterol to bile acid and bile acid excretion by inducing the expression of CYP7A.

Thyroid hormone not only has peripheral effects, but also has great impact on the central nervous system (CNS) which contributes a lot to global energy balance (Fig. 2). A recent animal study suggests that hyperthyroidism or central administration of T3 decreases the activity of hypothalamic AMP-activated protein kinase (AMPK), increases sympathetic nervous system (SNS) activity and upregulates thermogenic markers in brown adipose tissue, resulting in weight loss (Lopez et al., 2010). Either blockade of lipogenic

Table 1 Association of thyroid diseases, metabolic dysfunction and insulin resistance

\begin{tabular}{llll}
\hline & Whole body Insulin sensitivity & Liver & Peripheral tissues \\
\hline Hyperthyroidism & Impaired & Increased basal & Reduced peripheral \\
& glucose & hepatic glucose \\
tolerance & production & glucose utilization \\
Hypothyroidism & Insulin & Decreased & Decreased glucose \\
(rodent) & resistance & hepatic glucose & $\begin{array}{l}\text { utilization and turnover } \\
\text { (muscle and fat) }\end{array}$ \\
Resistance to & peduction of & Impaired & Accumulation of TG and \\
thyroid hormone & insulin & hepatic insulin & DAG; increased \\
& sensitivity & sensitivity (?) & mitochondrial uncoupling \\
& & & and FA oxidation \\
\end{tabular}

Note: The relationship between insulin sensitivity and thyroid dysfunction is shown in the table. Corresponding metabolic alterations, which may contribute to the whole body insulin sensitivity, in the liver and peripheral tissues are summarized. 


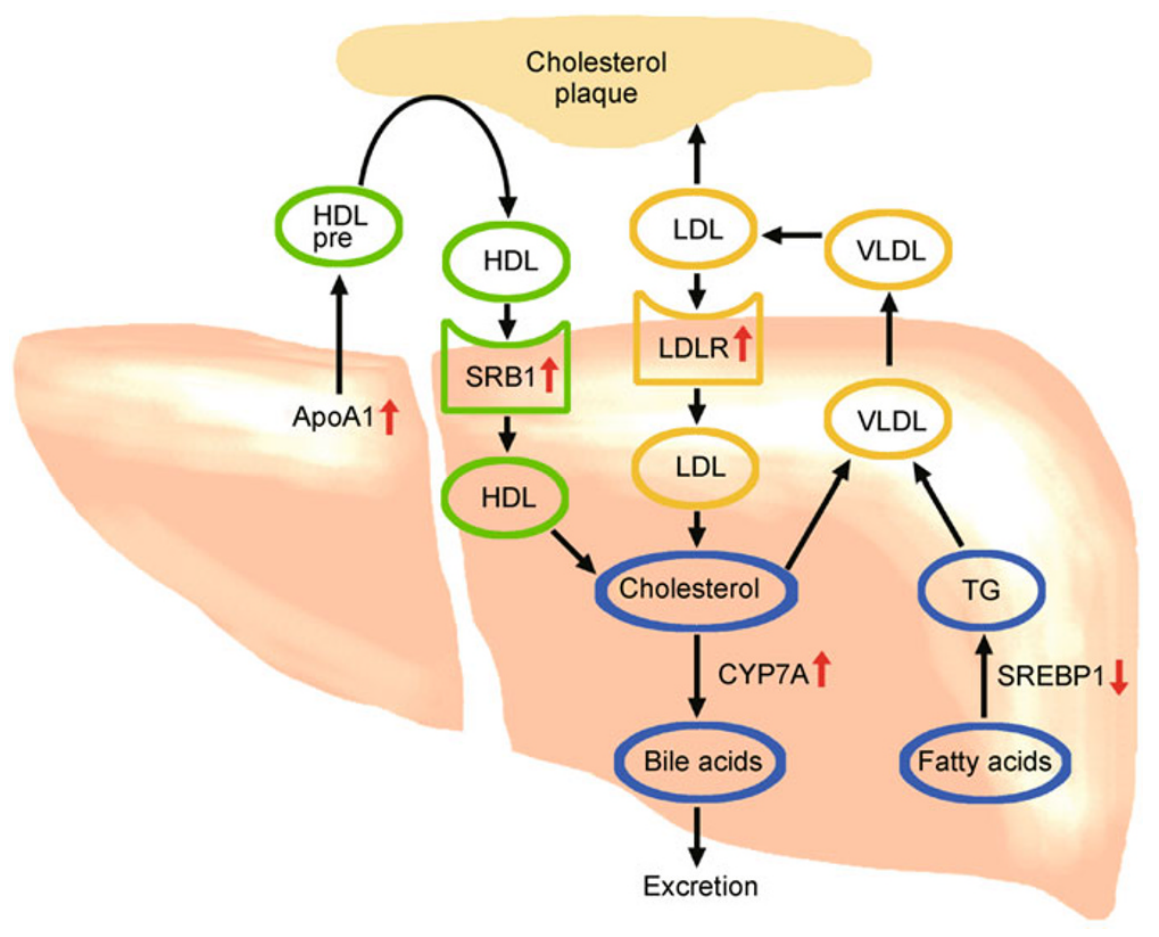

Figure 1. Possible mechanisms contributing to the beneficial effect of thyroid hormone mimetics. Low-density lipoprotein (LDL) and high-density lipoprotein (HDL) pathway, as well as liver triglyceride and cholesterol homeostasis, are orchestrated by multiple factors. Thyroid hormone mimetics increase HDL synthesis, HDL reuptake, LDL uptake, the conversion of cholesterol to bile acid, and decrease fatty acid synthesis by mediating the expression of apolipoprotein A1 (APOA1), scavenger receptor B1 (SRB1), LDL receptor (LDLR), cytochrome P450 7A (CYP7A), and sterol response element binding protein (SREBP1) as indicated, respectively.

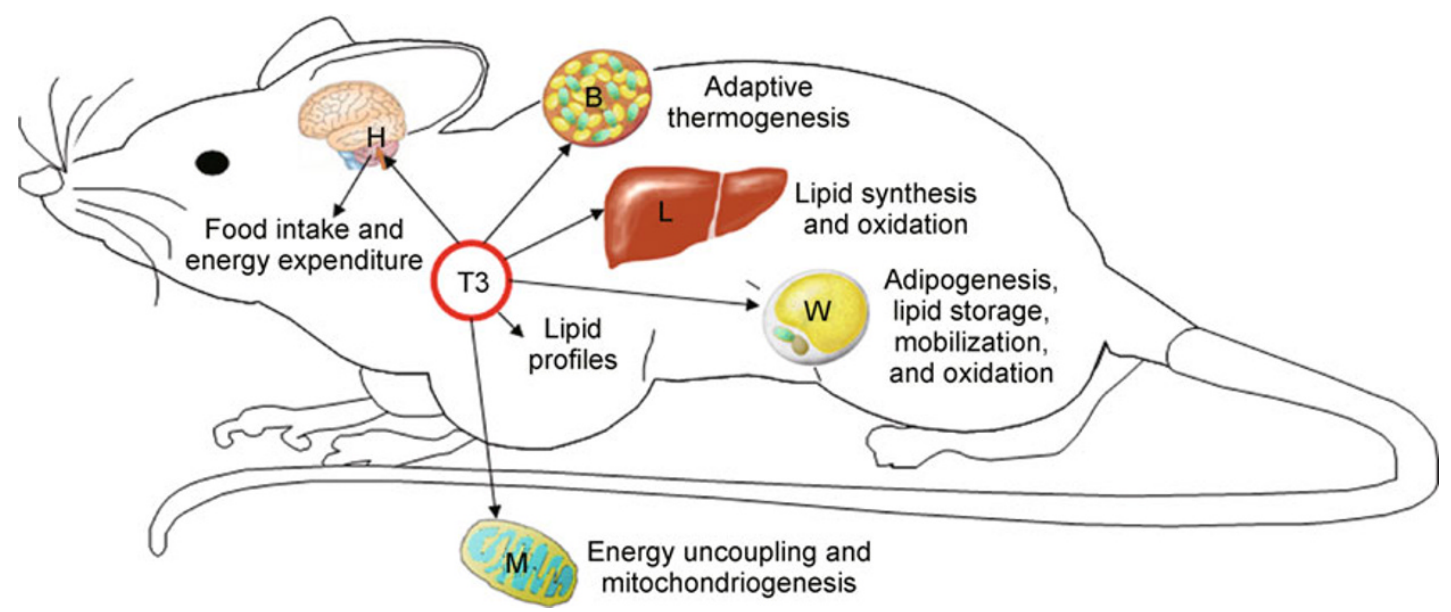

Figure 2. Schematic representation of the central and peripheral effects of thyroid hormone in metabolic regulation. Thyroid hormone actions in the hypothalamus $(H)$, brown adipose tissue $(B)$; white adipose tissue $(W)$, liver (L), and mitochondria (M) are summarized.

pathway in the ventromedial nucleus of the hypothalamus (VMH), or inhibition of TRs reverses hyperthyroidism associated weight loss and prevents CNS-mediated activation of
BAT. These observations indicate that thyroid hormone is able to modulate whole body energy homeostasis through regulating AMPK signaling in the hypothalamus. Whole 
body metabolic control by thyroid hormone could be initiated in CNS is further supported by studies of the type 4 melanocortin receptor (MC4R), a key relay in leptin signaling. MC4R is expressed by hypothalamic paraventricular thyrotropin-releasing hormone (TRH) neurons. It increases energy expenditure through increasing the production of TRH and T3 (Decherf et al., 2010). Hypothalamic MC4R activation reduces food intake and increases energy expenditure. Negative feedback by T3 causes repression of MC4R. Further detailed characterization identified negative thyroid hormone-response elements (nTREs) in the MC4R promoter. Such repression ensures that the energy-saving effects of $\mathrm{T} 3$ feedback on TRH are not overridden by MC4R activation. Taken together, these studies indicate that thyroid hormone controls energy homeostasis through its central effects on hypothalamus.

\section{Knock-in mouse models}

Since the phenotypes of TR $\alpha$ and TR $\beta$ knockout mice are not as striking as expected, loss-of-function approach was applied by generating knock-in mice for TR $\alpha$ and $T R \beta$ genes. Recently, great progress has been made in the understanding of thyroid hormone receptor isoformdependent actions in metabolic control by using these knockin mutant mice (Fig. 2).

Regulation of lipid homeostasis and adipogenesis in white adipose tissue

The evidence about how mutations of TRa1 lead to lipid abnormalities came from three TRa1 knock-in mice created by three research groups. A mutation, known as PV (Parrilla et al., 1991), was targeted to the TRa1 gene locus (TRa1PV mice). This mutant results in a complete loss of T3-binding activity and transcriptional capacity. Homozygous knock-in $\mathrm{TR} \alpha 1^{\mathrm{PV} / \mathrm{PV}}$ mice die soon after birth and heterozygous $\mathrm{TRa} 1^{\mathrm{PV} / \mathrm{N}}$ mice display a striking phenotype of dwarfism (Kaneshige et al., 2001). Compared to wild type mice, $\mathrm{TR} \alpha 1^{\mathrm{PV} / \mathrm{N}}$ mice have a significant reduction in inguinal, epididymal, and perirenal fat. In addition, serum levels of free fatty acids, total triglycerides, and leptin are decreased in $\mathrm{TR} \alpha 1^{\mathrm{PV} / \mathrm{N}}$ mice. Impaired adipogenesis in the white adipose tissue (WAT) of TRa1 ${ }^{\mathrm{PV} / \mathrm{N}}$ mice is due to repression of the PPARY signaling (Ying et al., 2007). Further studies indicate that PPARY expression is positively regulated via the binding of peroxisome proliferator response element (PPRE) by liganded TRa1, the major TR isoform in WAT. These observations suggest that TRa1PV dysregulates PPARY expression which results in impaired adipogenesis of WAT in TRa1 $1^{P V / N}$ mice. Similar to TRa1 $1^{P V / N}$ mice, the TRa1R384C knock-in mice exhibit a lean phenotype with reduction in white fat mass and decreased leptin levels (Sjögren et al., 2007). TRa1R384C mice are hypermetabolic and resistant to diet-induced obesity. Unlike findings in $\mathrm{TRa} 1^{\mathrm{PV} / \mathrm{N}}$ mice, the expression of PPARy does not change, while the expression levels of acetyl-CoA carboxylase (ACC) and PPAR a are elevated, indicating increased lipid mobilization and $\beta$ oxidation in WAT. The reduced lipolysis in adipocytes may contribute to the phenotype of TRa1R384C mice. In contrast to the lean phenotype in $\mathrm{TRa} 1^{\mathrm{PV} / \mathrm{N}}$ and $\mathrm{TR} \alpha 1 \mathrm{R} 384 \mathrm{C}$ mice, TRa1P398H mice show an increased body fat accumulation with elevated serum leptin level (Liu et al., 2003). The different phenotypes could reflect the differences in their differential T3 binding ability, diverse potency of dominant negative effect, and variable interaction of nuclear receptor coregulators (Kaneshige et al., 2001; Tinnikov et al., 2002; Liu et al., 2003). Unlike the abnormalities in WAT found in TRa1 knock-in mice, no apparent change in mass or morphology of WAT was observed in TR $\beta P V$ mice, in which PV was targeted to the TRß gene locus (Kaneshige et al., 2000; Araki et al., 2009), indicating that TRa1 plays a critical role in the regulation of lipid homeostasis in WAT.

\section{Regulation of lipid and glucose metabolism in liver}

Since TR $\beta 1$ is the major TR isoform in the liver (Cheng, 2000), it is conceivable to speculate abnormalities if the normal activity of TR $\beta 1$ is suppressed by its mutant. Compared with wild type mice, TR $\beta^{P V / P V}$ mice exhibit a significant increase in liver weight. Indeed, aberrant lipid accumulation and adipogenic steatosis are found in the liver of $T R \beta^{P V / P V}$ mice. Interestingly, the expression of lipogenic enzymes and PPARy, as well as downstream PPARy target genes which are adipocyte specific, is increased in the fatty liver of $T R \beta^{P V / P V}$ mice. On the other hand, the expression of carnitine palmitoyltransferase $1 \mathrm{~A}(\mathrm{Cpt} 1 \alpha)$ as well as the $\beta$-oxidation activity is decreased in the fatty liver of $T R \beta^{P V / P V}$ mice. The increased lipogenesis, adipogenesis and decreased $\beta$-oxidation all contribute to the hepatic steatosis of the TR $\beta^{P V / P V}$ mice (Araki et al., 2009). Using hypothyroid mice and thyroid hormone treatment, the expression of PPARY was found to be negatively regulated by thyroid hormone in liver. Because TR $\beta 1$ is the major TR isoform in the liver, when TR $\beta P V$ plays a dominant-negative role in the liver, PPARy expression could no longer be suppressed by the elevated thyroid hormone, thereby resulting in hepatic steatosis. In contrast, TRa1 ${ }^{\mathrm{PV} / \mathrm{N}}$ mice have very different phenotypes in liver. Compared with wild type mice, $T R a 1^{P V / N}$ mice have a significant reduction in both liver weight and liver lipids. Consistently, decreased expression of lipogenic enzymes and PPARY has been found in the liver of TRa1 ${ }^{\mathrm{PV} / \mathrm{N}}$ mice (Araki et al., 2009). Similar phenotype has also been reported in the liver of Thra1P398H mutant mice (Liu et al., 2003). Although these observations indicate that the regulation of lipid metabolism in the liver is thyroid hormone receptor isoform-dependent, the mechanisms are still not clear. 
Regulation of adaptive thermogenesis in brown adipose tissue

Thyroid hormone coordinates with adrenergic signaling in regulating effective adaptive thermogenesis in BAT (Rubio et al., 1995). A TRE has been reported in the promoter of UCP1 gene, indicating that thyroid hormone is at least important for UCP1 gene transcription (Branco et al., 1999). TRa1 deficient mice have decreased body temperature, suggesting TRa1 is required to maintain temperature homeostasis (Flamant and Samarut, 2003; Marrif et al., 2005). Using TR $\beta$-specific ligand, GC-1, a differential effect of different TR isoforms was revealed. TR $\beta 1$ is in charge of the transcription of UCP1, while TRa1 is required for adrenergic signaling (Ribeiro et al., 2001). Consistent with this finding, TRa1P398H mice are defective in adaptive thermogenesis when the mice are exposed to coldness (Liu et al., 2003). There are no differences in the expression levels of UCP1 between TRa1P398H mice and wild type mice, indicating that the transcriptional regulation of UCP1 by TR $\beta 1$ is not impaired in TRa1P398H mice. The participation of TR $\beta 1$ in adaptive thermogenesis via regulation of UCP1 expression was further confirmed by recent studies using TR $\beta P V$ mice (Ribeiro et al., 2010) with elevated serum level of thyroid hormone. Thus, adaptive thermogenesis in BAT is regulated by both TR isoforms via different mechanisms.

\section{Mitochondria}

The mitochondrion consumes metabolic fuels to generate ATP by oxidative phosphorylation. The coupling of fuel consumption to ATP generation is tightly controlled, while uncoupling of substrate oxidation to ATP generation produces heat. Basal metabolic rate and heat generation are controlled by thyroid hormone (Ledesma et al., 2002; Brand, 2005; Harper and Seifert, 2008; Kim, 2008). More recently, NMR approaches have demonstrated that T3 increases mitochondrial tricarboxylic acid (TCA) flux in skeletal muscle, without any effect on the rate of ATP synthesis, suggesting increased mitochondrial energy uncoupling (Lebon et al., 2001) (Fig. 2). The ability of thyroid hormone to increase the number of mitochondria in cells is well known. Two critical mitochondrial transcription regulators, PPAR gamma coactivator-1 (PGC-1) and the general mitochondrial transcription factor $A$, as well as $12 \mathrm{~S}$ and $16 \mathrm{~S}$ rRNA in mitochondria, are regulated by thyroid hormone, which may contribute to the direct effects of thyroid hormone on mitochondriogenesis (Fisher et al., 1992; Garstka et al., 1994; Wu et al., 1999; Marin-Garcia et al., 2000).

\section{Nervous system}

Thyroid hormone is necessary for the development and function of the nervous system. It has diverse effects on multiple processes including learning, anxiety-like behaviour and sensory function. In addition, thyroid hormone has been shown to regulate axonal outgrowth, hippocampal synaptic activity and the patterning of opsin photopigments necessary for colour vision in vitro (Nunez et al., 2008). The TR $\beta$ gene serves a prominent role in sensory systems. TR $\beta$ mutations cause deafness in mice and are associated with hearing loss in humans (Brucker-Davis et al., 1996; Forrest et al., 1996; Shibusawa et al., 2003). A TRa knock-in mutation causes anxiety-like symptoms, learning defects, and abnormalities in open field and fear conditioning tests (Guadaño-Ferraz et al., 2003; Venero et al., 2005; Wilcoxon et al., 2007). Glucose is the essential nutrient consumed by the brain to produce the energy for synaptic activity. Local glucose metabolism has been shown to be correlated with local neural activity. Recently, the glucose utilization has been studied in TR isoform-specific knock-in mice. The study demonstrated that a dominant negative mutation (PV) in TRa1 but not in TR $\beta$ impaired glucose utilization in the brain, suggesting the regulation of brain glucose utilization depends primarily upon TRa1 rather than TR $\beta$ (Itoh et al., 2001). Further studies are required to identify key genes and metabolic processes that mediate thyroid hormone action to understand how thyroid hormone determines diverse neurophysiological and neurodevelopmental events.

\section{PERSPECTIVES}

A growing number of discoveries suggest that TR $\alpha$ and TR $\beta$ play extensive and pivotal roles in energy homeostasis (Fig. 2). Isoform specific regulation becomes more interesting and requires further attention. We believe that advance in the following research fields will largely substantiate our understanding of thyroid hormone receptor isoform specific functions in energy metabolism.

\section{Transcriptional regulation}

The transcriptional regulation mediated by TR is not as clear as some other nuclear receptors, such as estrogen receptor (ER). TR may have its unique regulation due to its own transcriptional pattern, its stability, and its cellular location. To date, although many genes were shown to be regulated by thyroid hormone, less than 30 genes have been reported to contain TRE in their promoters. Given the fact that deep sequencing is widely used in ChIP-on-chip assay, we believe that TR direct target genes in the whole genome will come to light, which will further ascertain the consensus sequences of TRE. Usually, we found no difference between TRa1 and TR $\beta 1$ in overexpressing systems or in vitro systems. It is probably because most of cell lines lose the expression of endogenous TRs, and overexpressing systems with obvious leaking in cytoplasm are used. Whether TR isoforms have differential direct target genes needs further study. Recently 
antibodies against the A/B domain of TRa1 or TR $\beta 1$ have been developed and now are available from Rockland Immunochemicals. If these antibodies prove to be suitable for ChIP assay, they will be very useful to identify TR isoform specific target genes in vivo.

\section{Crosstalk with other nuclear receptors}

More and more studies showed nuclear receptors have crosstalk to coordinate the transcription of target genes. The crosstalk between two nuclear receptors could come up through one response element or through their own response elements in the promoter of a metabolic enzyme. Such crosstalks between two nuclear receptors make it possible in combining different mimetics to achieve a synergistic effect and reduce the dose-dependent toxicity. Carbohydrate responsive element-binding protein (ChREBP) and SREBP1 are liver $X$ receptor (LXR) target genes, while lipoprotein lipase (LPL) and Cpt1 $\alpha$ are PPAR target genes. These genes are key regulators of glucose and lipid metabolism. TR has been shown to regulate the transcription of these genes either through TRE or via response elements identified as LXRE or PPRE (Schoonjans et al., 1996; Jansen et al., 2000; Yoshikawa et al., 2001; Araki et al., 2005; Hashimoto et al., 2009; Gauthier et al., 2010). However, most studies were carried out in vitro. The interaction between TR and PPAR/LXR and the corresponding subsequent physiological events could be further elucidated by crossing TR mutant mice with PPAR and/or LXR knockout mice. The advance in this research field will further expand our knowledge of TR in lipid metabolism.

\section{Non-genomic effect of TR}

Recently the non-genomic effect of TR was extensively studied by several research groups all over the world (Moeller et al., 2005; Hiroi et al., 2006; Furuya et al., 2007). It is not clear whether non-genomic effect of TR also plays a role in sustaining energy metabolism. A recent study showed that AMPK activity is regulated by thyroid hormone in CNS (López et al., 2010); however, the authors did not point out whether such regulation belongs to non-genomic action of TR or not. In addition to AMPK signaling, MAPK and PI3K/AKT signaling have been shown to be regulated by thyroid hormone. Since these critical signaling pathways also control energy homeostasis, thyroid hormone might regulate metabolism via targeting these pathways. Whether there is an isoform-specific non-genomic action remains unclear. Systematic in vivo and in vitro experiments are required to address such a question.

\section{Conditional knockout or conditional inducible transgenic mice}

Due to the alteration in hypothalamus-pituitary-thyroid axis, all
TR transgenic mice including TRa knockout and knock-in mice have impaired thyroid hormone metabolism. Such a change, even minor in the thyroid hormone levels, may have great impact on the whole body metabolism, which will lead to false conclusion. One of current strategies to overcome this disadvantage is to render the mice to hypothyroid with methylimidazole (MMI) or propylthiouracil (PTU) treatment and then give mice certain amount of $\mathrm{T} 4$ or $\mathrm{T} 3$ to assure that all wild type mice and TR mutant mice have the same hormone level. However, it is not easy because wild type mice and mutant mice may have different turnover rates or metabolic rates of thyroid hormone (Ribeiro et al., 2010). Thus, the only way to exclude the circulating hormone effect is to use more advanced conditional knockout mice or conditional inducible transgenic mice. To be expected, the conditional TR knockout mice exhibit normal circulating hormone levels. Another way to study the differential effect of TR $\alpha$ and TR $\beta$ in a particular organ is to use conditional, tissue specific, inducible transgenic mice. Such transgenic mice may be more suitable for investigation of the molecular mechanisms underlying the metabolic regulation mediated by different TR isoforms.

\section{ACKNOWLEDGEMENTS}

We apologize to the scientists who made contributions to the field, but have not been cited due to space limitations. This review and studies in our laboratory were supported by grants from the One Hundred Talents Program of the Chinese Academy of Sciences, the National Basic Research Program (973 Program) (Grant Nos. 2009CB919000 and 2010CB912500), the National Natural Science Foundation of China (Grant Nos. 30970587 and 31070679), and the Science and Technology Commission of Shanghai Municipality (10ZR1435000).

\section{ABBREVIATIONS}

BAT, brown adipose tissue; CNS, central nervous system; PPARs, peroxisome proliferator-activated receptors; $\mathrm{RTH}$, resistance to thyroid hormone; RXR, retinoid X receptor; TRs, thyroid hormone nuclear receptors; TREs, thyroid hormone response elements; TRH, thyrotropin-releasing hormone; TSH, thyroid stimulating hormone; WAT, white adipose tissue

\section{REFERENCES}

Andersson, M.L., and Vennström, B. (1997). Chicken thyroid hormone receptor alpha requires the $\mathrm{N}$-terminal amino acids for exclusive nuclear localization. FEBS Lett 416, 291-296.

Araki, O., Ying, H., Furuya, F., Zhu, X., and Cheng, S.Y. (2005). Thyroid hormone receptor beta mutants: Dominant negative regulators of peroxisome proliferator-activated receptor gamma action. Proc Natl Acad Sci U S A 102, 16251-16256.

Araki, O., Ying, H., Zhu, X.G., Willingham, M.C., and Cheng, S.Y. (2009). Distinct dysregulation of lipid metabolism by unliganded thyroid hormone receptor isoforms. Mol Endocrinol 23, 308-315.

Bogazzi, F., Hudson, L.D., and Nikodem, V.M. (1994). A novel 
heterodimerization partner for thyroid hormone receptor. Peroxisome proliferator-activated receptor. J Biol Chem 269, 11683-11686.

Bradley, D.J., Towle, H.C., and Young, W.S. 3rd. (1994). Alpha and beta thyroid hormone receptor (TR) gene expression during auditory neurogenesis: evidence for TR isoform-specific transcriptional regulation in vivo. Proc Natl Acad Sci U S A 91, 439-443.

Branco, M., Ribeiro, M., Negrão, N., and Bianco, A.C. (1999). 3,5,3'Triiodothyronine actively stimulates UCP in brown fat under minimal sympathetic activity. Am J Physiol 276, E179-E187.

Brand, M.D. (2005). The efficiency and plasticity of mitochondrial energy transduction. Biochem Soc Trans 33, 897-904.

Braverman, L.E., Ingbar, S.H., and Sterling, K. (1970). Conversion of thyroxine (T4) to triiodothyronine (T3) in athyreotic human subjects. J Clin Invest 49, 855-864.

Brucker-Davis, F., Skarulis, M.C., Pikus, A., Ishizawar, D., Mastroianni, M.A., Koby, M., and Weintraub, B.D. (1996). Prevalence and mechanisms of hearing loss in patients with resistance to thyroid hormone. J Clin Endocrinol Metab 81, 2768-2772.

Casas, F., Rochard, P., Rodier, A., Cassar-Malek, I., MarchalVictorion, S., Wiesner, R.J., Cabello, G., and Wrutniak, C. (1999). A variant form of the nuclear triiodothyronine receptor cErbAalpha1 plays a direct role in regulation of mitochondrial RNA synthesis. Mol Cell Biol 19, 7913-7924.

Cettour-Rose, P., Theander-Carrillo, C., Asensio, C., Klein, M., Visser, T.J., Burger, A.G., Meier, C.A., and Rohner-Jeanrenaud, F. (2005). Hypothyroidism in rats decreases peripheral glucose utilisation, a defect partially corrected by central leptin infusion. Diabetologia 48, 624-633.

Chen, J.D., and Evans, R.M. (1995). A transcriptional co-repressor that interacts with nuclear hormone receptors. Nature 377 , 454- 457.

Cheng, S.Y. (2000). Multiple mechanisms for regulation of the transcriptional activity of thyroid hormone receptors. Rev Endocr Metab Disord 1, 9-18.

Cook, C.B., Kakucska, I., Lechan, R.M., and Koenig, R.J. (1992). Expression of thyroid hormone receptor beta 2 in rat hypothalamus. Endocrinology 130, 1077-1079.

Decherf, S., Seugnet, I., Kouidhi, S., Lopez-Juarez, A., ClergetFroidevaux, M.S., and Demeneix, B.A. (2010). Thyroid hormone exerts negative feedback on hypothalamic type 4 melanocortin receptor expression. Proc Natl Acad Sci U S A 107, 4471-4476.

Dimitriadis, G., Mitrou, P., Lambadiari, V., Boutati, E., Maratou, E., Panagiotakos, D.B., Koukkou, E., Tzanela, M., Thalassinos, N., and Raptis, S.A. (2006). Insulin action in adipose tissue and muscle in hypothyroidism. J Clin Endocrinol Metab 91, 4930-4937.

Fisher, R.P., Lisowsky, T., Parisi, M.A., and Clayton, D.A. (1992). DNA wrapping and bending by a mitochondrial high mobility group-like transcriptional activator protein. J Biol Chem 267, 3358-3367.

Flamant, F., and Samarut, J. (2003). Thyroid hormone receptors: lessons from knockout and knock-in mutant mice. Trends Endocrinol Metab 14, 85-90.

Forman, B.M., Casanova, J., Raaka, B.M., Ghysdael, J., and Samuels, H.H. (1992). Half-site spacing and orientation determines whether thyroid hormone and retinoic acid receptors and related factors bind to DNA response elements as monomers, homodimers, or heterodimers. Mol Endocrinol 6, 429 442.

Forrest, D., Erway, L.C., Ng, L., Altschuler, R., and Curran, T. (1996).
Thyroid hormone receptor beta is essential for development of auditory function. Nat Genet 13, 354-357.

Furuya, F., Ying, H., Zhao, L., and Cheng, S.Y. (2007). Novel functions of thyroid hormone receptor mutants: beyond nucleus-initiated transcription. Steroids 72, 171-179.

Garstka, H.L., Fäcke, M., Escribano, J.R., and Wiesner, R.J. (1994). Stoichiometry of mitochondrial transcripts and regulation of gene expression by mitochondrial transcription factor A. Biochem Biophys Res Commun 200, 619-626.

Gauthier, K., Billon, C., Bissler, M., Beylot, M., Lobaccaro, J.M., Vanacker, J.M., and Samarut, J. (2010). Thyroid hormone receptor beta (TRbeta) and liver $X$ receptor (LXR) regulate carbohydrateresponse element-binding protein (ChREBP) expression in a tissue-selective manner. J Biol Chem 285, 28156-28163.

Guadaño-Ferraz, A., Benavides-Piccione, R., Venero, C., Lancha, C., Vennström, B., Sandi, C., DeFelipe, J., and Bernal, J. (2003). Lack of thyroid hormone receptor alpha1 is associated with selective alterations in behavior and hippocampal circuits. Mol Psychiatry 8 , 30-38.

Harper, M.E., and Seifert, E.L. (2008). Thyroid hormone effects on mitochondrial energetics. Thyroid 18, 145-156.

Hashimoto, K., Ishida, E., Matsumoto, S., Okada, S., Yamada, M., Satoh, T., Monden, T., and Mori, M. (2009). Carbohydrate response element binding protein gene expression is positively regulated by thyroid hormone. Endocrinology 150, 3417-3424.

Hiroi, Y., Kim, H.H., Ying, H., Furuya, F., Huang, Z., Simoncini, T., Noma, K., Ueki, K., Nguyen, N.H., Scanlan, T.S., et al. (2006). Rapid nongenomic actions of thyroid hormone. Proc Natl Acad Sci U S A 103, 14104-14109.

Hodin, R.A., Lazar, M.A., and Chin, W.W. (1990). Differential and tissue-specific regulation of the multiple rat c-erbA messenger RNA species by thyroid hormone. J Clin Invest 85, 101-105.

Hodin, R.A., Lazar, M.A., Wintman, B.I., Darling, D.S., Koenig, R.J., Larsen, P.R., Moore, D.D., and Chin, W.W. (1989). Identification of a thyroid hormone receptor that is pituitary-specific. Science 244 , 76-79.

Hörlein, A.J., Näär, A.M., Heinzel, T., Torchia, J., Gloss, B., Kurokawa, R., Ryan, A., Kamei, Y., Söderström, M., Glass, C.K., et al. (1995). Ligand-independent repression by the thyroid hormone receptor mediated by a nuclear receptor co-repressor. Nature 377 , 397-404.

Hwang, J.H., Pan, J.W., Heydari, S., Hetherington, H.P., and Stein, D. T. (2001). Regional differences in intramyocellular lipids in humans observed by in vivo $1 \mathrm{H}-\mathrm{MR}$ spectroscopic imaging. J Appl Physiol 90, 1267-1274.

Itoh, Y., Esaki, T., Kaneshige, M., Suzuki, H., Cook, M., Sokoloff, L., Cheng, S.Y., and Nunez, J. (2001). Brain glucose utilization in mice with a targeted mutation in the thyroid hormone alpha or beta receptor gene. Proc Natl Acad Sci U S A 98, 9913-9918.

Izumo, S., and Mahdavi, V. (1988). Thyroid hormone receptor alpha isoforms generated by alternative splicing differentially activate myosin HC gene transcription. Nature 334, 539-542.

Jackson, I.M., Prentice, C.R., and McKiddie, M.T. (1970). The effect of hypothyroidism on glucose tolerance and insulin metabolism. J Endocrinol 47, 257-258.

Jansen, M.S., Cook, G.A., Song, S., and Park, E.A. (2000). Thyroid hormone regulates carnitine palmitoyltransferase lalpha gene expression through elements in the promoter and first intron. $J$ 
Biol Chem 275, 34989-34997.

Kaneshige, M., Kaneshige, K., Zhu, X., Dace, A., Garrett, L., Carter, T. A., Kazlauskaite, R., Pankratz, D.G., Wynshaw-Boris, A., Refetoff, S., et al. (2000). Mice with a targeted mutation in the thyroid hormone beta receptor gene exhibit impaired growth and resistance to thyroid hormone. Proc Natl Acad Sci U S A 97, 13209-13214.

Kaneshige, M., Suzuki, H., Kaneshige, K., Cheng, J., Wimbrow, H., Barlow, C., Willingham, M.C., and Cheng, S. (2001). A targeted dominant negative mutation of the thyroid hormone alpha 1 receptor causes increased mortality, infertility, and dwarfism in mice. Proc Natl Acad Sci U S A 98, 15095-15100.

Kim, B. (2008). Thyroid hormone as a determinant of energy expenditure and the basal metabolic rate. Thyroid 18, 141-144.

Köhrle, J. (2000). The selenoenzyme family of deiodinase isozymes controls local thyroid hormone availability. Rev Endocr Metab Disord 1, 49-58.

Krssak, M., Falk Petersen, K., Dresner, A., DiPietro, L., Vogel, S.M., Rothman, D.L., Roden, M., and Shulman, G.I. (1999). Intramyocellular lipid concentrations are correlated with insulin sensitivity in humans: a 1H NMR spectroscopy study. Diabetologia 42, 113-116.

Lebon, V., Dufour, S., Petersen, K.F., Ren, J., Jucker, B.M., Slezak, L. A., Cline, G.W., Rothman, D.L., and Shulman, G.I. (2001). Effect of triiodothyronine on mitochondrial energy coupling in human skeletal muscle. J Clin Invest 108, 733-737.

Ledesma, A., de Lacoba, M.G., and Rial, E. (2002). The mitochondrial uncoupling proteins. Genome Biol 3, REVIEW S3015.

Liu, Y.Y., Schultz, J.J., and Brent, G.A. (2003). A thyroid hormone receptor alpha gene mutation $(\mathrm{P} 398 \mathrm{H})$ is associated with visceral adiposity and impaired catecholamine-stimulated lipolysis in mice. J Biol Chem 278, 38913-38920.

López, M., Varela, L., Vázquez, M.J., Rodríguez-Cuenca, S., González, C.R., Velagapudi, V.R., Morgan, D.A., Schoenmakers, E., Agassandian, K., Lage, R., et al. (2010). Hypothalamic AMPK and fatty acid metabolism mediate thyroid regulation of energy balance. Nat Med 16, 1001-1008.

Macchia, P.E., Takeuchi, Y., Kawai, T., Cua, K., Gauthier, K., Chassande, O., Seo, H., Hayashi, Y., Samarut, J., Murata, Y., et al. (2001). Increased sensitivity to thyroid hormone in mice with complete deficiency of thyroid hormone receptor alpha. Proc Natl Acad Sci U S A 98, 349-354.

Marin-Garcia, J., Ananthakrishnan, R., and Goldenthal, M.J. (2000). Heart mitochondrial DNA and enzyme changes during early human development. Mol Cell Biochem 210, 47-52.

Marrif, H., Schifman, A., Stepanyan, Z., Gillis, M.A., Calderone, A., Weiss, R.E., Samarut, J., and Silva, J.E. (2005). Temperature homeostasis in transgenic mice lacking thyroid hormone receptoralpha gene products. Endocrinology 146, 2872-2884.

McKenna, N.J., Lanz, R.B., and O'Malley, B.W. (1999). Nuclear receptor coregulators: cellular and molecular biology. Endocr Rev 20, 321-344.

Meier-Heusler, S.C., Zhu, X., Juge-Aubry, C., Pernin, A., Burger, A. G., Cheng, S.Y., and Meier, C.A. (1995). Modulation of thyroid hormone action by mutant thyroid hormone receptors, c-erbA alpha 2 and peroxisome proliferator-activated receptor: evidence for different mechanisms of inhibition. Mol Cell Endocrinol 107, 55-66.

Mitsuhashi, T., Tennyson, G.E., and Nikodem, V.M. (1988).
Alternative splicing generates messages encoding rat c-erbA proteins that do not bind thyroid hormone. Proc Natl Acad Sci U S A 85, 5804-5808.

Moeller, L.C., Dumitrescu, A.M., and Refetoff, S. (2005). Cytosolic action of thyroid hormone leads to induction of hypoxia-inducible factor-1alpha and glycolytic genes. Mol Endocrinol 19, 2955-2963.

Nagy, L., Kao, H.Y., Chakravarti, D., Lin, R.J., Hassig, C.A., Ayer, D. E., Schreiber, S.L., and Evans, R.M. (1997). Nuclear receptor repression mediated by a complex containing SMRT, mSin3A, and histone deacetylase. Cell 89, 373-380.

Nunez, J., Celi, F.S., Ng, L., and Forrest, D. (2008). Multigenic control of thyroid hormone functions in the nervous system. Mol Cell Endocrinol 287, 1-12.

Okajima, F., and Ui, M. (1979). Metabolism of glucose in hyper- and hypo-thyroid rats in vivo. Glucose-turnover values and futile-cycle activities obtained with $14 \mathrm{C}$ - and $3 \mathrm{H}$-labelled glucose. Biochem J 182, 565-575.

Oppenheimer, J.H., Schwartz, H.L., Lane, J.T., and Thompson, M.P. (1991). Functional relationship of thyroid hormone-induced lipogenesis, lipolysis, and thermogenesis in the rat. J Clin Invest 87 , 125-132.

Pagliarini, D.J., Calvo, S.E., Chang, B., Sheth, S.A., Vafai, S.B., Ong, S.E., Walford, G.A., Sugiana, C., Boneh, A., Chen, W.K., et al. (2008). A mitochondrial protein compendium elucidates complex I disease biology. Cell 134, 112-123.

Parrilla, R., Mixson, A.J., McPherson, J.A., McClaskey, J.H., and Weintraub, B.D. (1991). Characterization of seven novel mutations of the c-erbA beta gene in unrelated kindreds with generalized thyroid hormone resistance. Evidence for two "hot spot" regions of the ligand binding domain. J Clin Invest 88, 2123-2130.

Petersen, K.F., Blair, J.B., and Shulman, G.I. (1995). Triiodothyronine treatment increases substrate cycling between pyruvate carboxylase and malic enzyme in perfused rat liver. Metabolism 44, 1380-1383.

Petersen, K.F., Cline, G.W., Blair, J.B., and Shulman, G.I. (1994). Substrate cycling between pyruvate and oxaloacetate in awake normal and 3,3'-5-triiodo-L-thyronine-treated rats. Am J Physiol 267, E273-E277.

Pihlajamäki, J., Boes, T., Kim, E.Y., Dearie, F., Kim, B.W., Schroeder, J., Mun, E., Nasser, I., Park, P.J., Bianco, A.C., et al. (2009). Thyroid hormone-related regulation of gene expression in human fatty liver. J Clin Endocrinol Metab 94, 3521-3529.

Raboudi, N., Arem, R., Jones, R.H., Chap, Z., Pena, J., Chou, J., and Field, J.B. (1989). Fasting and postabsorptive hepatic glucose and insulin metabolism in hyperthyroidism. Am J Physiol 256, E159-E166.

Randin, J.P., Scazziga, B., Jéquier, E., and Felber, J.P. (1985). Study of glucose and lipid metabolism by continuous indirect calorimetry in Graves' disease: effect of an oral glucose load. J Clin Endocrinol Metab 61, 1165-1171.

Ribeiro, M.O., Bianco, S.D., Kaneshige, M., Schultz, J.J., Cheng, S. Y., Bianco, A.C., and Brent, G.A. (2010). Expression of uncoupling protein 1 in mouse brown adipose tissue is thyroid hormone receptor-beta isoform specific and required for adaptive thermogenesis. Endocrinology 151, 432-440.

Ribeiro, M.O., Carvalho, S.D., Schultz, J.J., Chiellini, G., Scanlan, T. S., Bianco, A.C., and Brent, G.A. (2001). Thyroid hormonesympathetic interaction and adaptive thermogenesis are thyroid 
hormone receptor isoform—specific. J Clin Invest 108, 97-105.

Roos, A., Bakker, S.J., Links, T.P., Gans, R.O., and Wolffenbuttel, B. H. (2007). Thyroid function is associated with components of the metabolic syndrome in euthyroid subjects. J Clin Endocrinol Metab 92, 491-496.

Rubio, A., Raasmaja, A., Maia, A.L., Kim, K.R., and Silva, J.E. (1995). Effects of thyroid hormone on norepinephrine signaling in brown adipose tissue. I. Beta 1- and beta 2-adrenergic receptors and cyclic adenosine 3',5'-monophosphate generation. Endocrinology 136, 3267-3276.

Sap, J., Muñoz, A., Damm, K., Goldberg, Y., Ghysdael, J., Leutz, A., Beug, H., and Vennstrñm, B. (1986). The c-erb-A protein is a highaffinity receptor for thyroid hormone. Nature 324, 635-640.

Schoonjans, K., Peinado-Onsurbe, J., Lefebvre, A.M., Heyman, R.A., Briggs, M., Deeb, S., Staels, B., and Auwerx, J. (1996). PPARalpha and PPARgamma activators direct a distinct tissue-specific transcriptional response via a PPRE in the lipoprotein lipase gene. EMBO J 15, 5336-5348.

Schräder, M., Müller, K.M., Nayeri, S., Kahlen, J.P., and Carlberg, C. (1994). Vitamin D3-thyroid hormone receptor heterodimer polarity directs ligand sensitivity of transactivation. Nature 370, 382-386.

Shen, D.C., Davidson, M.B., Kuo, S.W., and Sheu, W.H. (1988). Peripheral and hepatic insulin antagonism in hyperthyroidism. J Clin Endocrinol Metab 66, 565-569.

Shibusawa, N., Hashimoto, K., Nikrodhanond, A.A., Liberman, M.C., Applebury, M.L., Liao, X.H., Robbins, J.T., Refetoff, S., Cohen, R. N., and Wondisford, F.E. (2003). Thyroid hormone action in the absence of thyroid hormone receptor DNA-binding in vivo. J Clin Invest 112, 588-597.

Sinha, R., Dufour, S., Petersen, K.F., LeBon, V., Enoksson, S., Ma, Y. Z., Savoye, M., Rothman, D.L., Shulman, G.I., and Caprio, S. (2002). Assessment of skeletal muscle triglyceride content by (1) $\mathrm{H}$ nuclear magnetic resonance spectroscopy in lean and obese adolescents: relationships to insulin sensitivity, total body fat, and central adiposity. Diabetes 51, 1022-1027.

Sjögren, M., Alkemade, A., Mittag, J., Nordström, K., Katz, A., Rozell, B., Westerblad, H., Arner, A., and Vennström, B. (2007). Hypermetabolism in mice caused by the central action of an unliganded thyroid hormone receptor alpha1. EMBO J 26, 4535-4545.

Ting, Y.T., Bhat, M.K., Wong, R., and Cheng, S. (1997). Tissuespecific stabilization of the thyroid hormone beta1 nuclear receptor by phosphorylation. J Biol Chem 272, 4129-4134.

Ting, Y.T., and Cheng, S.Y. (1997). Hormone-activated phosphorylation of human beta1 thyroid hormone nuclear receptor. Thyroid 7 , 463-469.

Tinnikov, A., Nordström, K., Thorén, P., Kindblom, J.M., Malin, S., Rozell, B., Adams, M., Rajanayagam, O., Pettersson, S., Ohlsson, C., et al. (2002). Retardation of post-natal development caused by a negatively acting thyroid hormone receptor alpha1. EMBO J 21, 5079-5087.
Venero, C., Guadaño-Ferraz, A., Herrero, A.I., Nordström, K., Manzano, J., de Escobar, G.M., Bernal, J., and Vennström, B. (2005). Anxiety, memory impairment, and locomotor dysfunction caused by a mutant thyroid hormone receptor alpha1 can be ameliorated by T3 treatment. Genes Dev 19, 2152-2163.

Wagner, B.K., Kitami, T., Gilbert, T.J., Peck, D., Ramanathan, A., Schreiber, S.L., Golub, T.R., and Mootha, V.K. (2008). Large-scale chemical dissection of mitochondrial function. Nat Biotechnol 26, 343-351.

Wagner, R.L., Apriletti, J.W., McGrath, M.E., West, B.L., Baxter, J.D., and Fletterick, R.J. (1995). A structural role for hormone in the thyroid hormone receptor. Nature 378, 690-697.

Weinberger, C., Thompson, C.C., Ong, E.S., Lebo, R., Gruol, D.J., and Evans, R.M. (1986). The c-erb-A gene encodes a thyroid hormone receptor. Nature 324, 641-646.

Wilcoxon, J.S., Nadolski, G.J., Samarut, J., Chassande, O., and Redei, E.E. (2007). Behavioral inhibition and impaired spatial learning and memory in hypothyroid mice lacking thyroid hormone receptor alpha. Behav Brain Res 177, 109-116.

Wrutniak, C., Cassar-Malek, I., Marchal, S., Rascle, A., Heusser, S., Keller, J.M., Fléchon, J., Dauça, M., Samarut, J., Ghysdael, J., et al. (1995). A 43-kDa protein related to c-Erb A alpha 1 is located in the mitochondrial matrix of rat liver. J Biol Chem 270, 16347-16354.

Wu, Z., Puigserver, P., Andersson, U., Zhang, C., Adelmant, G., Mootha, V., Troy, A., Cinti, S., Lowell, B., Scarpulla, R.C., et al. (1999). Mechanisms controlling mitochondrial biogenesis and respiration through the thermogenic coactivator PGC-1. Cell 98, 115-124.

Yen, P.M. (2001). Physiological and molecular basis of thyroid hormone action. Physiol Rev 81, 1097-1142.

Yen, P.M., Sunday, M.E., Darling, D.S., and Chin, W.W. (1992). Isoform-specific thyroid hormone receptor antibodies detect multiple thyroid hormone receptors in rat and human pituitaries. Endocrinology 130, 1539-1546.

Ying, H., Araki, O., Furuya, F., Kato, Y., and Cheng, S.Y. (2007). Impaired adipogenesis caused by a mutated thyroid hormone alpha1 receptor. Mol Cell Biol 27, 2359-2371.

Yoshikawa, T., Shimano, H., Amemiya-Kudo, M., Yahagi, N., Hasty, A.H., Matsuzaka, T., Okazaki, H., Tamura, Y., lizuka, Y., Ohashi, K., et al. (2001). Identification of liver $X$ receptor-retinoid $X$ receptor as an activator of the sterol regulatory element-binding protein $1 \mathrm{c}$ gene promoter. Mol Cell Biol 21, 2991-3000.

Zhang, X.K., and Pfahl, M. (1993). Hetero- and homodimeric receptors in thyroid hormone and vitamin A action. Receptor 3 , 183-191.

Zhu, X.G., McPhie, P., and Cheng, S.Y. (1997). Differential sensitivity of thyroid hormone receptor isoform homodimers and mutant heterodimers to hormone-induced dissociation from deoxyribonucleic acid: its role in dominant negative action. Endocrinology 138 , 1456-1463. 